\title{
MEDIDAS DE CONTROLE DE EROSÃO EM ESTRADAS RURAIS NA BACIA DO RIO DAS PEDRAS, GUARAPUAVA-PR
}

\section{Erosion control measures of rural roads in the Rio das Pedras basin, Guarapuava, Paraná (Brazil)}

\author{
Márcia Cristina da Cunha \\ Mestre em Geografia pela UNICENTRO, Guarapuava \\ marcialcunha@yahoo.com.br
}

\author{
Edivaldo Lopes Thomaz \\ Prof. Adjunto, Depto. de Geografia, UNICENTRO, Guarapuava, Bolsista CNPq \\ thomaz@unicentro.br \\ Leandro Redin Vestena \\ Prof. Adjunto, Depto. de Geografia, UNICENTRO, Guarapuava \\ lvestena@unicentro.br
}

Artigo recebido em 11/04/2012 e aceito para publicação em 12/10/2012

RESUMO: O traçado das estradas que cortam grande número de rios e a drenagem lateral nas estradas faz com que as águas cheguem rapidamente à rede de drenagem aumentando a vazão. Disso resulta grande produção de sedimentos haja vista que algumas estradas e caminhos internos não possuem dissipadores de energia. Portanto o presente trabalho teve por objetivo analisar e discutir o sistema viário das estradas rurais da bacia do Rio das Pedras, Guarapuava-PR e a construção de caixas de contenção como medida preventiva para dissipar energia e conseqüentemente a entrada de sedimentos nos canais fluviais. No estudo utilizou-se de dados cartográficos e de campo para mensurar as estradas rurais e as caixas de contenção. Por meio da análise dos resultados constatou-se que o número de caminhos internos supera as estradas principais, que em grande parte não possui dissipadores de energia, potencializando a entrada de sedimentos nos cursos d'água. Ao todo foram selecionados dez pontos aleatoriamente na bacia e foram verificados 792 cruzamentos de estradas rurais e cursos d'água. Nas estradas rurais com caixas de contenção verificou-se que em torno de $70 \%$ destas encontravam-se inativas, havendo uma deterioração em média de $10 \%$ do total de caixas de contenção mensuradas a cada dois anos.

Palavras-chave: Bacia hidrográfica, Recursos hídricos, relevo declivoso, sedimentação.

ABSTRACT: The layout of roads that cross many rivers, and the lateral drainage roads causes water to move quickly to the drainage network by increasing the flow rate. This results in high sediment yield considering that some roads and have no internal energy sinks. Therefore this study aimed to analyze and discuss the road system of the rural roads of the Rio das Pedras, PR Guarapuava-boxes and the construction of containment as a preventive measure of dissipate energy and hence the entry of sediment in river channels. In this study we used the cartographic data and field to measurement of rural roads and containment boxes. By analyzing the results it was found that the number of paths exceeds the internal main roads, which largely does not have sinks of energy, enhancing the entry of sediments into waterways. Altogether ten points were selected randomly and were verified in the basin 792 intersections of rural roads and waterways. In rural roads containment boxes it was found that about $70 \%$ thereof were inactive, and there is a deterioration in average $10 \%$ of total containment boxes measured every two years.

Keywords: Watershed, Water resources, Sloping topography, Siltation. 


\section{INTRODUÇÃO}

Com o progresso da humanidade, houve uma intensa intervenção na apropriação dos recursos naturais e conseqüente alteração deste. Neste contexto, o estudo da complexa dinâmica hidrossedimentológica de uma bacia hidrográfica mostra-se fundamental para a tomada de decisões sobre o planejamento dos recursos naturais, porque representam a principal fonte de captação de água para o consumo.

O estudo de processos hidrológicos nas bacias hidrográficas também é relevante quando se analisa o uso da água e a possível falta da mesma para abastecer a demanda mundial (PACHECHENIK, 2004). Por sua vez, a bacia hidrográfica do Rio das Pedras (BRP) é um dos principais mananciais de água do município de Guarapuava, região centro sul do Estado do Paraná.

Na BRP o uso da terra é essencialmente rural, e por consequência possui um sistema viário composto em sua maioria por estradas rurais não pavimentadas que vão interferir nos processos hidrossedimentológicos e geomorfológicos.

Oda et al., (2007) destacam que no Brasil, grande extensão da rede viária é composta por estradas não pavimentadas. Elas são o principal meio de escoamento da produção agropecuária. Apesar de sua extensão e da grande importância econômica e social, as estradas não pavimentadas é um tema pouco estudado, e muitas vezes relegado a segundo plano.

Thomaz (2009) destaca que boa parte da região Centro-Sul do Paraná (ex. bacia do Rio das Pedras) são terras dissecadas, ocupadas por agricultura familiar, florestas e reflorestamento. Nas terras dissecadas, as estradas, carreadores e caminhos são implantados em diferentes unidades geomorfopedológicas e muitas vezes não é considerada a aptidão do terreno. Por outro lado, a conservação das estradas rurais em terras dissecadas é realizada com dificuldade. Deste modo, muitos carreadores e caminhos internos das propriedades tornam-se intransitáveis devido ao forte ravinamento que se instala sobre o leito dessas vias de circulação.

Os sistemas de gerenciamento de vias (es- tradas rurais), é constituído por um elenco de atividades coordenadas, relacionadas ao planejamento, que envolvem projeto, construção, manutenção, avaliação e pesquisa, constituindo a ferramenta que pode ajudar os organismos rodoviários na otimização do uso deste recurso, ODA et al., (2007).

Incontestável sua implantação para a locomoção, as estradas carecem de investigações mais específicas voltadas para o planejamento do seu uso adequado e de seus impactos nos recursos hídricos. É neste contexto que se tornam necessárias as pesquisas referentes aos elementos presentes nas paisagens (estradas não pavimentadas), na tentativa de mitigar os problemas gerados pela sua implantação, existência e manutenção.

Fontana (2007) enfatiza que o aumento na concentração dos sedimentos ocorre após as práticas de manutenção das estradas. Grace III (2000) alerta que apesar de a erosão do solo e o escoamento serem influenciados por muitos fatores, como a precipitação local e as características do solo, o manejo adotado também constitui fator de grande contribuição ao processo erosivo e que a chave para reduzir a quantidade de sedimentos entregue aos rios é identificar a origem dessa erosão.

Diante dos danos ambientais e econômicos que as estradas rurais podem provocar ao homem, tanto por sua falta quanto pela forma com que é implantada e mantida, associado aos poucos estudos específicos sobre o assunto percebe-se, um importante campo de pesquisa visando um maior conhecimento dessa problemática para que venham fornecer conhecimento da dinâmica dos processos hidrossedimentológicos para a prevenção e a mitigação dos danos ocasionados por elas.

Uma das formas que o poder público de Guarapuava encontrou para amenizar esses danos foi à implantação de caixas de contenção nas estradas rurais da BRP. As caixas de contenção são trincheiras profundas instaladas nas laterais das estradas com o objetivo de reter sedimento e água produzida principalmente no leito das estradas. Sua função é armazenar e dissipar energia evitando que a água escoe por longos trechos, causando erosão do solo durante sua passagem.

Dessa forma, as caixas servem para acu- 
mular o volume de água e sedimentos produzidos, sobretudo, nas estradas. Vale destacar que as caixas não foram implantadas de forma uniforme em todas as estradas existentes na bacia, e sim nos locais que mais necessitavam de medidas conservacionistas, BATTISTELLI et al., (2004).

O presente estudo busca caracterizar o sistema viário da BRP (largura de estrada, altura do barranco, ravinamento, distribuição de estradas) bem como avaliar a implantação de medidas de controle de sedimentos em estradas rurais, mais especificamente, de caixas de contenção, para redução da quantidade de sedimentos no Rio das Pedras. Diante disso, esta pesquisa tem como finalidade avaliar as estradas rurais não pavimentadas da bacia hidrográfica do Rio das Pedras em relação a seus efeitos nos processos hidrogeomorfológicos.

\section{MATERIAIS E MÉTODOS}

\section{Area de estudo}

A BRP possui área de aproximadamente 330 $\mathrm{km}^{2}$, localiza-se no município de Guarapuava, no Estado do Paraná, entre as latitudes $25^{\circ} 13^{\prime} 10^{\prime \prime} \mathrm{S}$ e $25^{\circ} 26^{\prime} 24^{\prime \prime} \mathrm{S}$ e longitudes $51^{\circ} 13^{\prime} 10^{\prime \prime} \mathrm{W}$ e $51^{\circ} 28^{\prime} 40^{\prime \prime}$ W (Figura 1).

O Rio das Pedras é um dos principais formadores do Rio Jordão, que por sua vez é um dos maiores afluentes da margem direita do Rio Iguaçu. O Rio das Pedras está instalado na unidade de rochas básicas da Formação Serra Geral. Na Bacia Sedimentar do Paraná essa unidade é a que possui maior extensão superficial, constituindo substrato de significativa porção da paisagem geomorfológica (LIMA, 2009).

Figura 1. Localização da bacia hidrográfica do Rio das Pedras em relação ao município de Guarapuava

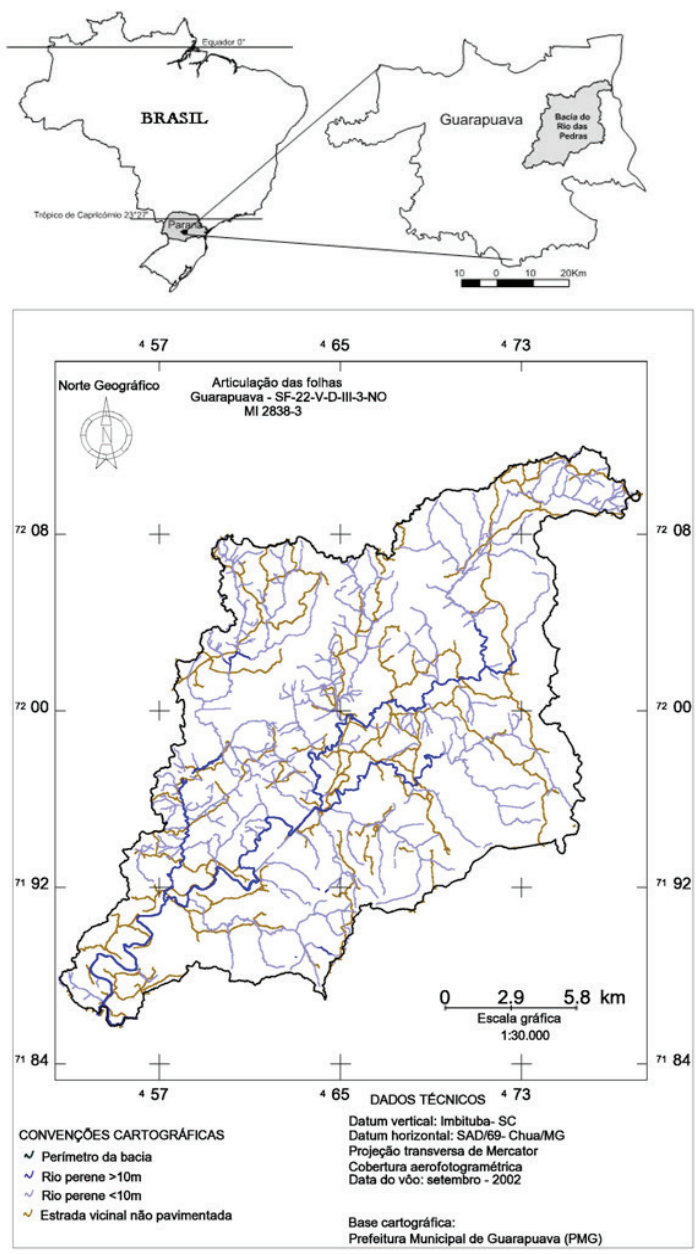

Elaboração dos autores. 
Ressalta-se também que as principais nascentes que formam o Rio das Pedras encontram-se na Área de Proteção Ambiental (APA) da Serra da Esperança, instituída pela Portaria Federal n. 507/02, de 17 de dezembro de 2002. Em relação ao clima de Guarapuava, está sob o domínio da zona extratropical, o que resulta em temperaturas com caráter mesotérmico, temperaturas anuais médias entre $16^{\circ} \mathrm{e}$ $20^{\circ} \mathrm{C}$, inverno frio e verão amenizado pelas altitudes. A pluviosidade mostra-se bem distribuída ao longo do ano, com precipitações médias anuais em torno de $1.961 \mathrm{~mm}$ (THOMAZ e VESTENA, 2003). A classificação climática do município, segundo Köppen, classifica-se como $\mathrm{Cfb}$, o que significa que o clima é pluvial, sempre úmido, com verões chuvosos e frescos (MAACK, 1981).

O uso da terra, de modo geral, na BRP é diversificado, envolvendo atividades relacionadas à agricultura, a pecuária, a indústria, ao florestamento/ reflorestamento, mata, campo, capoeira entre outras. A água para abastecimento público da cidade de Guarapuava é captada na bacia do Rio das Pedras. Diante disso, a forma correta do uso da terra na BRP é fundamental para prevenção e/ou mitigação problemas ambientais.

Os procedimentos metodológicos adotados compreenderam trabalho de gabinete, realizado no Laboratório de Geoprocessamento (LABOGEO) do Departamento Geografia da UNICENTRO e de campo, para levantamento de dados sobre o sistema viário e rede drenagem e checagem das informações obtidas com o auxílio de um GPS (Sistema de Posicionamento Global).

A base cartográfica utilizada foi a Carta Topográfica de Guarapuava editada pelo Ministério do Exército, Departamento de Engenharia e Comunicações. A articulação das folhas SG22-V-D-III-3NO/ MI 2838-3 e a Base Cartográfica da Prefeitura Municipal de Guarapuava (PMG); escala: 1:30.000; (equidistância das curvas de nível: 5 metros); Projeção Transversa de Mercator (UTM); Meridiano Central: $51^{\circ}$ W. GR; Datum Vertical: Imbituba-SC, Datum Horizontal: SAD 69 - Chuá-MG; Cobertura aereofotogramétrica: Data do vôo: setembro/2002. Projeto número 647/02, autorização do MD n ${ }^{\circ} 135 / 02$. Convênio Secretaria do Meio Ambiente (SEMAFLOR), Agência
Nacional de Águas (ANA), Prefeitura Municipal de Guarapuava, Universidade Estadual do Centro-Oeste (UNICENTRO), executado por consórcio pela Empresa de Aerofotogrametria Engefoto.

O banco de dados foi obtido por meio de fotointerpretação das ortofotocartas disponível em formato digital (escala 1:30.000) (Prefeitura Municipal de Guarapuava, PMG 2008), utilizando-se do software SPRING - INPEC Versão 5.1.7 - Sistema de Processamento de Informações Georreferenciadas (Copyright - Instituto Nacional de Pesquisas Espaciais - INPE), desenvolvido pela Divisão de Processamento de Imagens - DPI do Instituto Nacional de Pesquisas Espaciais (INPE).

Os mapas elaborados foram: localização da bacia do Rio das Pedras, rede viária e rede de drenagem. A partir do banco de dados foi realizada análise morfométrica da densidade de drenagem e extensão do percurso superficial.

- Densidade da drenagem (Dd): correlaciona o comprimento total dos canais de escoamento com a área da bacia hidrográfica. A densidade de drenagem foi inicialmente definida por Horton (1945), e é calculada pela equação:

$$
D d=\frac{L t}{A}
$$

Na qual $D d$ corresponde à densidade da drenagem, $L t$ é o comprimento total de canais e $A$ é área da bacia.

- Extensão do percurso superficial (Eps): representa a distância média percorrida pelas enxurradas antes de encontrar um canal permanente, sendo calculado da seguinte forma:

$$
E p s=\frac{1}{2 D d}
$$

Na qual Eps a extensão do percurso superficial e $D d$ a densidade de drenagem. 
A escolha das duas análises morfométricas citadas se deve ao fato de dar uma base da capacidade de drenagem da bacia e também quantos metros a enxurrada percorre até chegar ao canal mais próximo, facilitando a interpretação dos resultados.

Para cálculo do número de cruzamento de canais fluviais $\mathrm{X}$ estradas foram selecionados dez pontos de controle aleatoriamente ao longo da bacia, para estimar o número total de cruzamentos em toda área da bacia. Essa proximidade do curso d'água e estrada rural facilita a entrada de sedimento nos canais fluviais. Os pontos selecionados para contagem tiveram como objetivo atingir todas as unidades da bacia, alta, média e baixa vertente. A partir dessas unidades selecionadas foi avaliada a proximidade dos canais fluviais com as estradas, largura média das estradas, ravinamento, altura do barranco, disponibilidade de material para transporte entre outras características importantes na obtenção dos resultados.

Em relação às caixas de contenção, estas foram classificadas em caixas ativas e caixas inativas utilizando-se de critério visual. As caixas ativas são aquelas que armazenam água e sedimentos provenientes principalmente das estradas. As caixas inativas são aquelas deterioradas, incapazes de armazenar água ou sedimento trazido pela enxurrada.

\section{RESULTADOS E DISCUSSÃO}

\section{Distribuição e características das estradas rurais bacia do Rio das Pedras}

As estradas rurais superam os caminhos internos que se distribuem em todas as unidades geomorfopedológica da BRP. Na bacia a maioria das estradas não possui dissipadores de energia, e as que possuem essas medidas de controle de erosão (caixas de contenção), em grande parte não estão cumprindo sua função de armazenar água e sedimentos.

$\mathrm{Na}$ BRP constatou-se que uma das peculiaridades do sistema das estradas rurais é que seu leito geralmente acompanha o fundo de vale (estradas principais), e os caminhos internos se distribuem em todas as unidades do terreno da bacia. Estes caminhos são mais representativos (74\%) que as estradas principais, como se observa na Tabela 1.

Tabela 1. Rede viária da bacia hidrográfica do Rio das Pedras

\begin{tabular}{lcc}
\hline Tipo de Rede Viária & Rede Viária $(\mathrm{km})$ & Rede Viária $(\%)$ \\
\hline Rodovia federal pavimentada & 21,2 & 1,8 \\
\hline Estrada vicinal pavimentada & 16,7 & 1,4 \\
\hline Estrada vicinal não pavimentada & 270,6 & 22,4 \\
Caminhos & 895,9 & 74,0 \\
Ferrovia & 5,0 & 0,4 \\
Total & $1.209,6$ & 100,0 \\
\hline
\end{tabular}

Fonte: Base cartográfica da Prefeitura Municipal de Guarapuava (PMG); escala: 1:30.000

Org. dos autores.

Notou-se em campo que em alguns casos as estradas e caminhos internos, foram implantados em unidades com declividade superior a $10^{\circ}$, o que em eventos pluviométricos potencializa a ação da enxurrada causando degradação, além de prejuízos econômicos. Outra característica desses caminhos é que são manuseados em grande parte pelos próprios moradores locais. A largura média desses caminhos é de 3 a 4 m de largura (freqüência 70\%).

No caso da bacia do Rio das Pedras, grande parte de estradas são de solos argilosos, o que facilita os problemas em épocas de chuva, como por exemplo, os atoleiros e a pista escorregadia. As características das estradas da bacia de maneira geral têm largura 
média de $5 \pm 0,8 \mathrm{~m}$ (freqüência $50 \%, \mathrm{n}=20$ ). Possuem ravinamento no sentido transversal e longitudinal da faixa de rolamento, com disponibilidade de material solto para ser transportado, (Figura 2. A).

Figura 2. Estradas não pavimentadas.

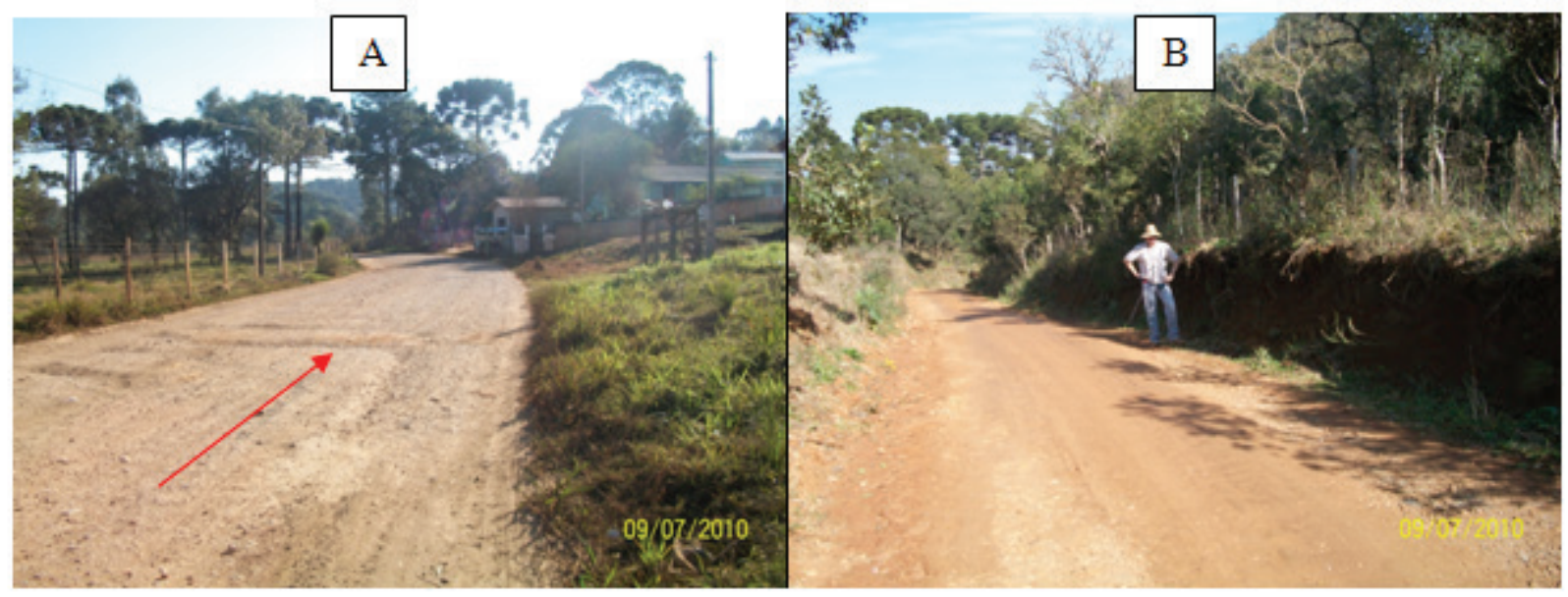

Em A, estrada com declividade de $2^{\circ}$, ravinamento e ausência de dissipador de energia, degradação no leito da estrada, presença de material disponível para transporte. Em B, estrada entre dois taludes, altura média de 1,15m, talude com exposição à luz do sol no lado esquerdo e repouso no lado direito da figura.

Foto dos autores.

Outro aspecto observado na Figura 2. B foi a inexistência de um sistema de drenagem. A estrada fica entre dois taludes impedindo à dissipação do escoamento superficial, e neste caso a declividade da estrada propicia um aumento na velocidade do escoamento, e conseqüentemente uma perda de solo maior e a criação de pequenos sulcos erosivos nos caminhos preferenciais da via.

Em alguns locais a declividade da estrada chega a $15^{\circ}$ que associado a ausência de dissipadores de energia, facilita o escoamento superficial e a conseqüente entrada de sedimentos no leito dos rios provocando turbidez prejudicando a vida aquática e a qualidade da água.

Idoraldo Júnior (2006) afirma que a estrada rural construída e mantida de forma inadequada sempre teve grande influência sobre o meio ambiente, determinando prejuízos consideráveis no leito e nas regiões lindeiras. Com o passar dos anos percebeu-se que grande parte dos problemas ambientais no meio rural tinha contribuição de águas drenadas no leito de estradas inadequadas, sem práticas de conservação, tanto na região lindeira quanto nas erosões iniciadas nas laterais destas estradas ou nas enormes voçorocas formadas pela manutenção equivocada destes caminhos.

Ressalta que entre as principais influências das estradas estão: a interferência no movimento de água e sedimento na bacia de drenagem; aumento no escoamento superficial e produção de sedimento e, sobretudo, ampliação da conexão entre vertente e canal fluvial (LUCE; WEMPLE 2001).

\section{Conexão da rede viária com a rede de drenagem}

Fredriksen (1970) e Versfeld (1981) verificaram que o aumento do escoamento superficial e da erosão não resulta diretamente das atividades florestais em si, como, por exemplo, o corte e o desbaste, mas sim são processos de ocorrência localizada, sendo originados principalmente nas estradas, nos carreado- 
res e em áreas compactadas. Assim, o planejamento adequado destas atividades torna-se necessário para alcançar um controle mais efetivo da erosão.

Para Lugo e Gucinski (2000), é difícil separar os efeitos hidrológicos dos efeitos geomorfológicos das estradas porque a água é geralmente o agente para o transporte de sedimentos nas bacias hidrográficas e as estradas influenciam ambos os processos. Os autores destacam ainda que a intensidade de transporte, o tipo de superfície de estrada, a vegetação de cobertura, o clima o substrato geológico, a manutenção das estradas e conectividade estrada-rio são fatores primários na regulação da produção de sedimentos nos sistemas de estradas.
Corroborando com essa afirmação constatou-se que a rede de drenagem acumulou comprimento total de segmentos (rios perenes) de 453,34 km, sendo a densidade de drenagem estimada em $1,37 \mathrm{~km} / \mathrm{km}^{2}$. Já a rede viária (estrada vicinal não pavimentada e caminhos) registrou $1.166,6 \mathrm{~km}$, conseqüentemente a densidade de estradas foi $3,53 \mathrm{~km} / \mathrm{km}^{2}$, ou seja, quase duas vezes maior que a densidade de drenagem natural. Somando-se a rede drenagem natural e a rede viária a extensão atinge $1.619,9 \mathrm{~km}$, aumentando a densidade para $4,9 \mathrm{~km} / \mathrm{km}^{2}$. Por conseguinte, com acréscimo da densidade total com a inclusão das estradas foi $72 \%$ superior de quando se considerou apenas a drenagem natural (Figura 3).

Figura 3. Rede viária e rede de drenagem da bacia hidrográfica do Rio das Pedras

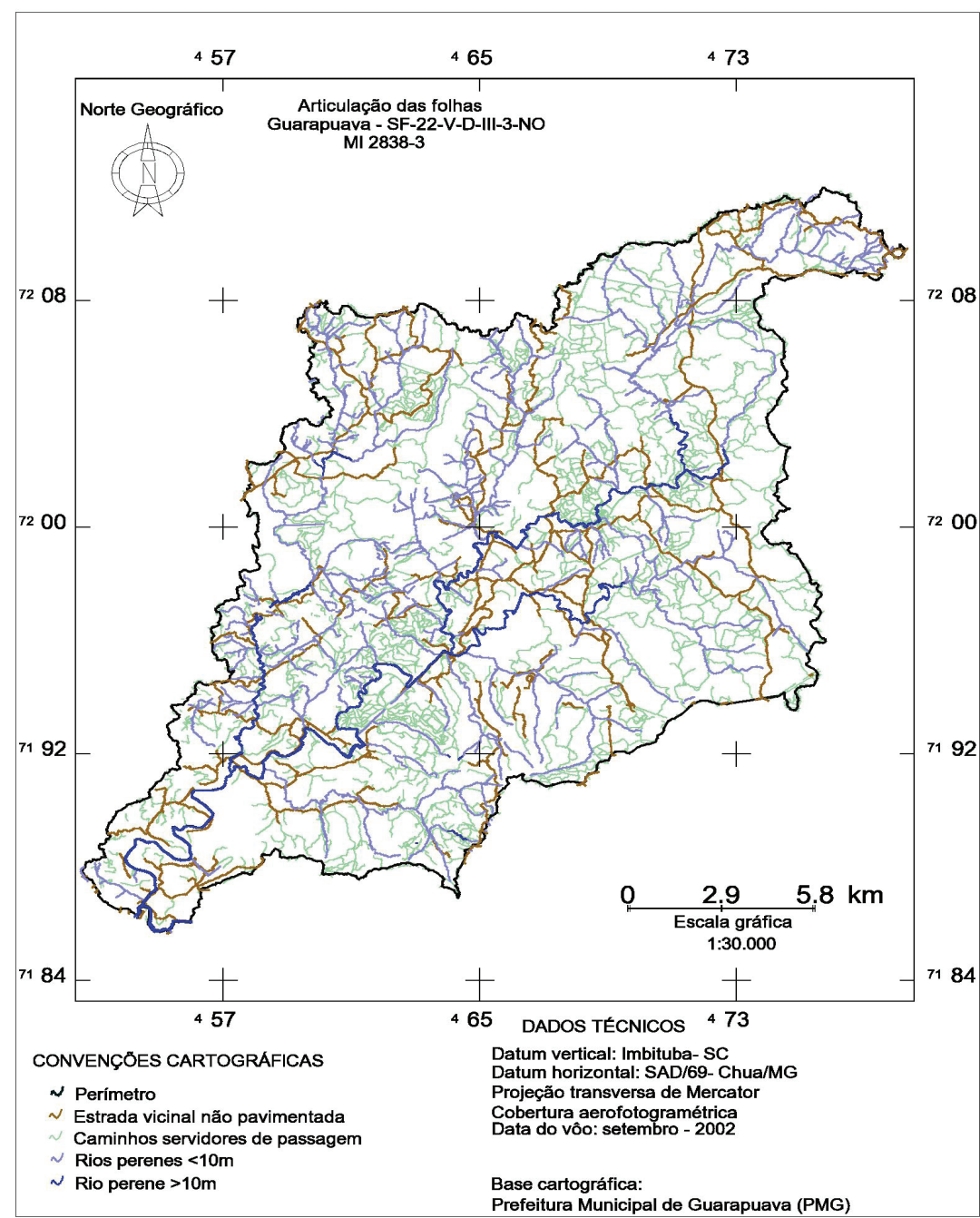

Elaboração dos autores. 
Tradicionalmente os estudos de erosão em vertentes são conduzidos de forma pontual. Assim, não ocorre a integração entre os processos de vertente e de rio. A identificação de proveniência de sedimento destaca-se devido à importância de quantificar a contribuição (absoluta e relativa) das diversas fontes de sedimento existente em uma bacia, (THOMAZ et al., 2011).

À distância percorrida pela enxurrada é outro fator importante. Segundo Horton (1945) a Extensão do Percurso Superficial (Eps) representa a distância média percorrida pelas enxurradas entre o interflúvio e o canal permanente, influenciada pela densidade de drenagem.

As estradas, na maioria das vezes, tornam-se canais efêmeros durante as chuvas. Assim, quando se compara a Eps obtida apenas com a densidade de drenagem natural, com a obtida com a densidade de drenagem natural mais as estradas verifica-se uma diminuição considerável na distancia média percorrida pelas enxurradas, mostrando que as vias de circulação afetam os processos hidrológicos e fisiográficos em bacias de drenagem.

A Eps referente à rede de drenagem natural na BRP é de $364 \mathrm{~m}$, porém, quando se considera a rede viária, a Eps é de $141 \mathrm{~m}$. Portanto, a Eps obtida considerando a rede viária é 2,5 vezes inferior à obtida somente com a rede de drenagem natural. Dessa forma pode-se considerar que as estradas potencializam a entrada de sedimentos nos canais fluviais uma vez que a enxurrada chega primeiro nas estradas antes de atingir o canal fluvial.

Gonçalves (2002), Baesso e Gonçalves (2003) chamam a atenção de que a correta localização das estradas na paisagem é o que as define como aceitáveis do ponto de vista ambiental, pois estradas adequadamente traçadas permitem que os impactos ambientais sejam menores. Como princípios básicos, o traçado deve ser localizado o mais próximo possível aos divisores de água, principalmente quando as estradas forem principais, e deve-se evitar a construção de estradas em áreas úmidas, instáveis, com fortes rampas e perto das áreas de preservação permanente.

Partindo deste princípio as estradas rurais na BRP, em boa parte, estão localizadas de forma inadequada, estando hidrologicamente conectadas aos canais fluviais por meio de cruzamentos, favorecendo a entrada de sedimentos nos corpos hídricos. A construção de dessas estradas seguindo o fundo de vale ocorre porque em relevo dissecado os setores de relevo próximo aos rios tende a serem mais planos.

Em dez áreas selecionadas aleatoriamente no âmbito da bacia, foram estimados que os há em média 2,4 $\pm 1,34$ cruzamentos (estrada $\mathrm{X}$ rio)/ $\mathrm{km}^{2}$. Considerando que a área da bacia é de aproximadamente $330 \mathrm{~km}^{2}$, estima-se que o número total de cruzamentos estrada-rio seja em torno de 792. Na bacia foram considerados apenas os cruzamentos em rios perenes, com as estradas vicinais não pavimentadas e caminhos internos. Deste modo, essas estradas devem ser ponderadas nas pesquisas de conservação de solo e da água em bacias hidrográficas rurais.

Segundo Catelani et al., (2004) a proximidade das vias em relação à rede de drenagem em bacias hidrográficas com relevo dissecado, agravada pela ausência de drenagem superficial adequada e contenção dos processos de erosão de taludes, na construção dessas vias, potencializa a ação da força hidráulica das enxurradas como agente de remoção e transporte de material em direção aos cursos d'água.

\section{Medidas de controle de sedimentos (caixas de contenção)}

Considerando as estradas como fontes de sedimentos em eventos pluviométricos, causando grandes impactos ambientais, principalmente, a qualidade da água, a prefeitura de Guarapuava, no ano de 2003 implantou caixas de contenção ao longo das estradas rurais da BRP, com o intuito de mitigar o aporte de sedimentos nos rios, provocados principalmente pela erosão hídrica nas estradas rurais (CUNHA; THOMAZ, 2008).

Para a prevenção e o controle do escoamento superficial e de sedimentos, bem como para a minimização das consequências negativas provocadas pela intervenção antrópica e o uso da terra, pode-se implantar caixas de contenção, que tem como objetivo garantir a estabilização dos processos decorrentes da produção de sedimentos, bem como recuperar as áreas (estradas) já degradadas, sendo eficientes, econômicas e aplicadas conforme as necessidades locais. 
O principal objetivo destas caixas é o armazenamento das águas das chuvas, reduzindo ao mínimo suas perdas nesses períodos, retirando a água do leito das estradas, servindo como dissipadoras de energia, facilitando a infiltração da água no solo. As caixas têm como objetivo também evitar que as descargas de bueiros ou sarjetas sejam lançadas diretamente em terrenos agricultáveis ou desprotegidos, acelerando o processo erosivo.

As caixas que servem para armazenar água e sedimentos são aqui chamadas de caixas ativas, e as que não estão aptas para desempenhar esta função são chamadas de caixas inativas, como pode se observar na Figura 4. Essas medidas corretoras foram implantadas para minimizar os problemas identificados da drenagem na área, para garantir que o escoamento superficial não ocorra com uma velocidade muito elevada, o que vem provocando a perda de solo, a formação de processos erosivos e poluindo os recursos hídricos com sedimentos em suspensão.

Figura 4. Caixas de contenção

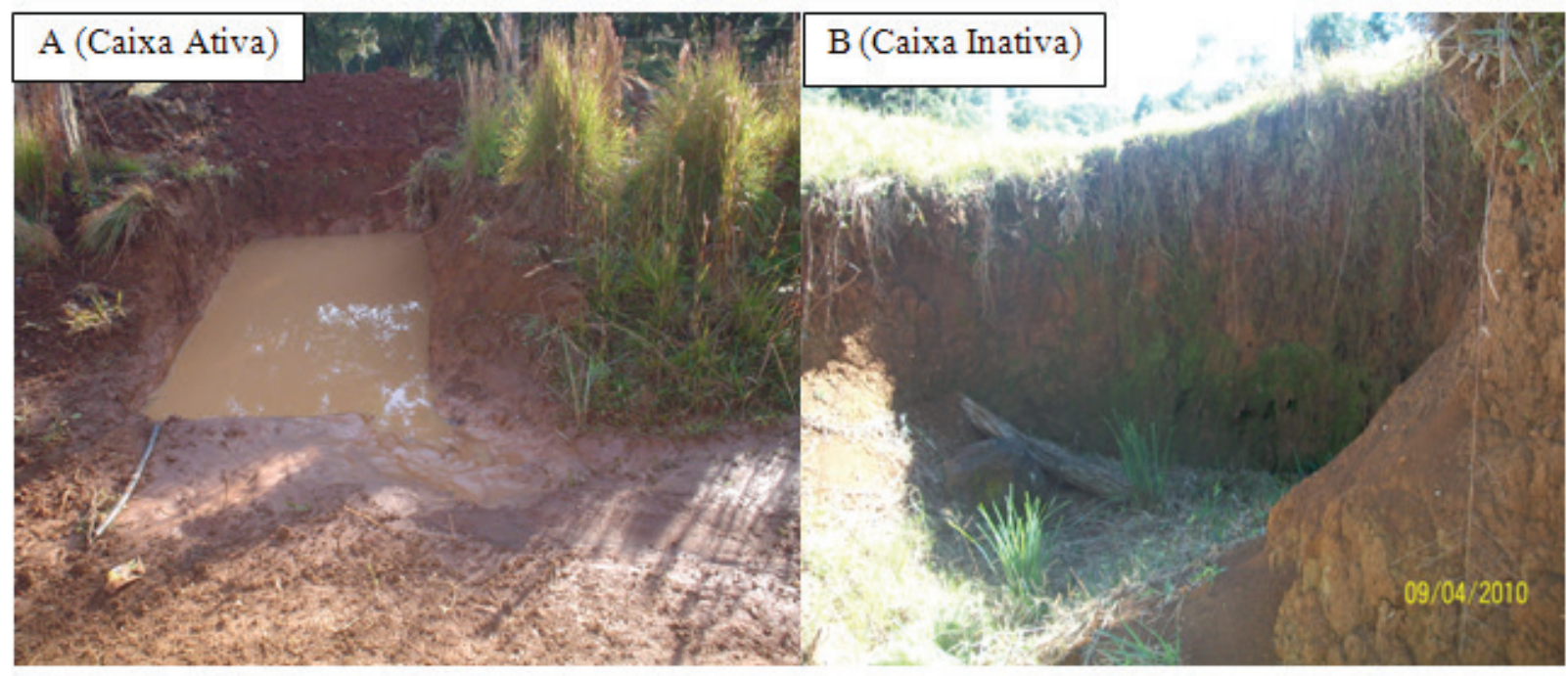

Em A, caixa ativa (2003) dissipando enxurrada, armazenando água e sedimentos produzidos, sobretudo nas estradas rurais evitando o transporte de sedimento e a entrada do mesmo no canal fluvial; em B caixa inativa (2010), deteriorada, sem manutenção e sem capacidade de armazenar água e sedimento.

Foto dos autores.

Apesar do benefício gerado pelas caixas de contenção, se elas não passarem por manutenções periódicas, elas perdem sua eficiência gradativamente. Na BRP verificou-se que após um ano em média da construção das caixas de contenção elas passam a perder gradativamente sua função de armazenar água e sedimento produzido principalmente nas estradas rurais.

Mensurações realizadas em 2008 verificaram-se 83 caixas em um trecho de $(4,2 \mathrm{~km})$, e deste total $25(30 \%)$ caixas encontravam-se ativas e $58(70 \%)$ estavam inativas. Posteriormente em outra avaliação em 2010 constatou-se que, do total de 83 caixas da mesma área de estudo, 17 (20\%) estavam ativas e 66 $(80 \%)$ caixas estavam inativas, ou seja, houve uma deterioração, em dois anos, de $10 \%$ do total de caixas mensuradas. Esta comparação do total de caixas deterioradas neste período pode ser mais bem visualizada na Figura 5. A e B. 
Figura 5. Comparação das caixas ativas e inativas

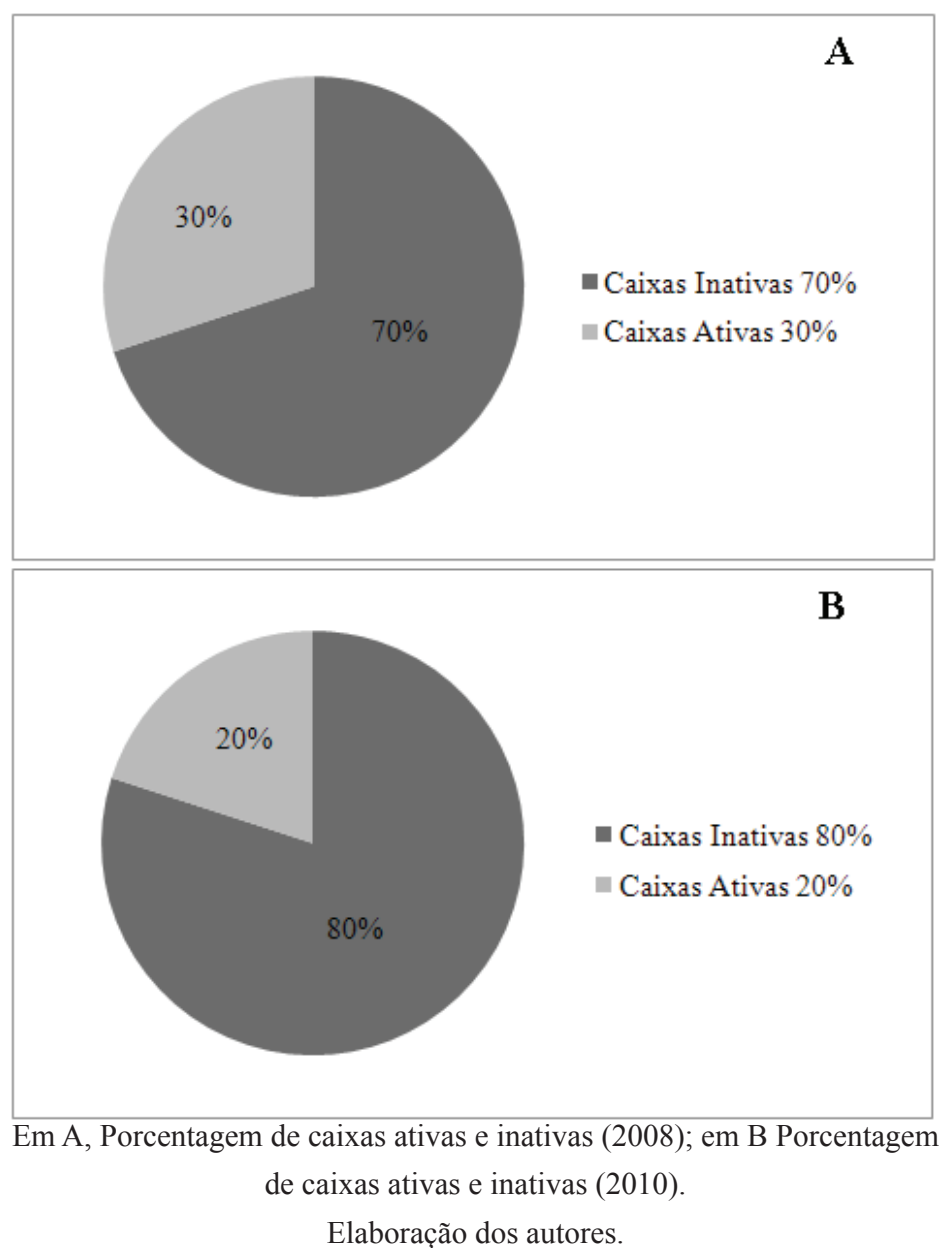

Quanto à manutenção, uma das medidas que pode ser tomada para a melhoria das caixas é o aumento da profundidade, porque em locais onde o lençol freático é mais raso pode aflorar água. Uma limpeza periódica se faz fundamental, permitindo uma melhor conservação das mesmas. Dessa forma nota-se que, se as caixas permanecessem em bom estado de conservação, poderiam armazenar uma boa quantidade de água e sedimento, servindo como depósito dos sedimentos transportados, e contribuindo para uma diminuição na quantidade de sedimento que entra nos canais fluviais.

No entanto, para que isso ocorra é recomendável que as caixas estejam em bom estado de conservação, com dimensões aproximadas ao seu estado inicial já padronizado na construção $\left(12 \mathrm{~m}^{3}\right)$.

Baesso e Gonçalves (2003) reforçam que as caixas devem sofrer manutenção frequente após cada período de chuva, verificando a existência de material carregado pelo fluxo de água, que deverá ser removido; limpeza da pelícola de argila que se forma no fundo da caixa, impedindo a infiltração da água no solo; recomposição da vegetação de proteção junto aos taludes da caixa, para protegê-la contra erosão, e a limpeza das canais de admissão à caixas de contenção.

Vale lembrar que existem alguns aspectos negativos em relação às caixas de contenção: quando não há manutenção podem gerar mau cheiro devido à água parada, nesses locais há presença de insetos e algumas servem como depósito de lixo ou de destinação final de animais mortos, daí a relevância de realizar limpeza nas caixas.

Se estas estiverem em bom estado de conservação podem armazenar grande quantidade do volume de água e sedimentos produzidos, evitando que che- 
guem aos corpos hídricos, diminuido o processo de assoreamento, turbidez, matéria orgânica, poluentes, entradas de resíduos sólidos nos corpos hídricos, entre outros benefícios.

Existem, ainda, limitações para realizar limpeza após cada período de chuva, devido ao custo de manutenção, porém é importante que seja realizada ao menos uma limpeza por ano.

\section{CONCLUSÕES}

1) Conclui-se que em relação ao sistema viário da BRP os caminhos internos (74\%) superam as estradas vicinais não pavimentadas $(22 \%) \mathrm{e}$ se distribuem em todas as unidades da bacia, e que nem sempre são manejados de forma correta acelerando o processo de erosão no leito dessas vias. Estes em sua maioria não possuem nenhum tipo de proteção (vegetação, dissipador de energia) potencializando o aumento de sedimentos.

2) As estradas rurais em grande parte não possuem dissipadores de energia que associado à declividade contribui ainda mais para o escoamento superficial. Outro aspecto observado é que as estradas geralmente acompanham o fundo de vale, o que não é recomendado pela literatura, uma vez que estas deveriam ser implantadas em sua maioria nos divisores topográficos, havendo até mesmo uma carência de pesquisa nessa área, uma vez que os terrenos dissecados são impróprios para implantação de estradas. Por conseguinte, existem muitos cruzamentos de estradas rurais com canais fluviais média de $2,4 \mathrm{~km} / \mathrm{km}^{2} \pm 0,8(\mathrm{n}=792)$, e evidentemente essa conexão facilita a entrada de sedimentos nos cursos d'água contribuindo alteração da qualidade da água.

3) A extensão do percurso superficial em relação à rede viária (28\%) é significativamente inferior à rede de drenagem (72\%). Portanto, as enxurradas em sua maioria irão atingir em primeiro momento as vias rurais e só posteriormente os canais fluviais, potencializando ainda mais a entrada dos sedimentos nestes cursos d'água.

4) A partir de 2003 quando foram implantadas as caixas de contenção, constatou-se que $80 \%$ estavam inativas em um trecho mensurado em 2010. Sendo assim essa condição não permite que as mesmas desempenhem o papel que é desviar o escoamento superficial para que ele não acumule sobre o leito da estrada e cause mais erosão.

\section{AGRADECIMENTOS}

Ao CNPq: Apoio financeiro, Edital MCT/ CNPq 15/2007- Universal- Faixa B (processo 475161/2007-6) Projeto: Avaliação do aporte de sedimento proveniente de estradas rurais e de seus impactos na descarga sólida fluvial em suspensão, na bacia do Rio Guabiroba, Guarapuava-PR. À Fundação Araucária apoio financeiro, projeto: Avaliação de processos hidro-erosivos em estradas rurais por meio de chuva simulada e análise da eficácia de medidas de controle de sedimento na bacia hidrográfica do Rio das Pedras (Chamada do Projeto n. 14/2009Fundação Araucária). À CAPES (Coordenação de Aperfeiçoamento de Pessoal de Nível Superior) por ter concedido bolsa.

\section{REFERÊNCIAS}

BAESSO, D. P. GONÇALVES, F. L. R. Estradas rurais: técnicas adequadas de manutenção. Florianópolis: DER, 2003. 204 p.

BATTISTELLI, N. VALERA, S. A. R. HEERDT, B. Uso da terra da bacia hidrográfica do Rio das Pedras. In: Mauro Battistelli; Maurício Camargo Filho; Bettina Heerdt. (Org.). Proteção e Manejo da Bacia do Rio das Pedras. Guarapuava: Editora B \& D Ltda, 2004, v. 1, p.100-108.

CATELANI, C. S., BATISTA, G. T., TARGA, M. S. Uso do geoprocessamento na determinação da distância entre estradas de rurais e a drenagem de uma microbacia hidrográfica: Rio das Antas. In: Encontro de Iniciação Científica, Universidade de Taubaté (UNITAU), Taubaté. 2004. Livro de Resumos, p.139, 2004. 
CUNHA, M. C. THOMAZ, E. L. Caracterização preliminar das medidas de controle de sedimentos (caixas de contenções) nas estradas rurais da bacia do Rio Guabiroba, Guarapuava-PR. In: XIX SEMINÁRIO DE PESQUISA E XIV SEMANA DE INICIAÇÃO CIENTÍFICA. Anais... Guarapuava-PR, 2008.

FONTANA, C. R. O efeito do nivelamento de estradas florestais na produção de sedimentos. Dissertação (Mestrado). USP, Escola Superior de Agricultura- Luis de Queiroz. Piracicaba, 2007. 80 p.

FREDRIKSEN, R. L. Erosion and sedimentation following road construction and timber harvest on unstable soils in three small western Oregon watersheds. Portland, Oregon: USDA, Forest Service. 1970, p. 1-15.

GONÇALVES, J. L. M. Conservação do solo. In. GONÇALVES, J. L. M.; STAPE, J. L. (Ed). Conservação e cultivo de solos para plantações florestais. Piracicaba: IPEF, 2002. cap. 2, p. 47-129.

GRACE III, J. M. Forest road sideslopes and soil conservation techniques. Journal of Soil and Water Conservation, Ankeny, v. 55, p. 1-9, 2000.

HORTON, R. E. Erosional development of streams and their drainage basins: a hydrophysical approach to quantitative morphology. Geol Soe. Am. Bull. v.56, n.3, p.275-370, 1945.

IDORALDO JÚNIOR, D. G. Estradas rurais: componente mobilizador do PEMH. II Fórum Ambiental da Alta Paulista. Tupã, 2006.

LIMA, A. G. Controle geológico e hidráulico na morfologia do perfil longitudinal em rio sobre rochas vulcânicas básicas da formação serra geral no estado do Paraná. Tese (Doutorado). Universidade Federal de Santa Catarina. Florianópolis, 2009, 240p.,

LUCE, C. H; WEPLE, B.C. Introduction to special issue on hydrologic and geomorphic of forest roads. Earth Surface Processes and Landforms, v. 26, p.111-113, 2001.
LUGO, A. E.; GUCINSKI, H. Function, effects, and management of forest roads. Forest Ecology and Management, Amsterdam, v. 133, p. 249-262, 2000.

MAACK, R. Geografia Física do Estado do Paraná. 3aed. Curitiba: Imprensa oficial, 1981, 440p.

ODA, S. FERNANDES JÚNIOR, J. F. SÓRIA, M. H. A. Implantação, localização e manutenção de estradas. Departamento de Transporte - EESC-USP, Universidade de São Paulo, 2007.

PACHECHENIK, P. E. Caracterização hidrológica e da fragilidade ambiental na bacia do Rio das Pedras, Guarapuava - PR. (Dissertação de Mestrado), Universidade Federal do Paraná, Curitiba-PR, 2004.

THOMAZ, E. L. VESTENA, L. R. Aspectos Climáticos de Guarapuava-PR. Guarapuava: UNICENTRO, 2003.

THOMAZ, E. L. Avaliação de processos hidro-erosivos em estradas rurais por meio de chuva simulada e análise da eficácia de medidas de controle de sedimento na bacia hidrográfica do Rio das Pedras, Guarapuava-PR. Projeto Fundação Araucária-apoio ao desenvolvimento científico e tecnológico do Paraná. Chamada de Projetos 14/2009 Programa de Apoio à Pesquisa Básica e Aplicada., Guarapuava, 2009 (mimeo).

THOMAZ, E. L.; ANTONELI, V.; DIAS, W. Estimativa de proveniência de sedimento em cabeceira de drenagem com alta densidade de estradas rurais não pavimentadas. Revista Brasileira de Recursos Hídricos, v. 16, p. 25-37, 2011.

VERSFELD, D. B. Overland flow on small plots at the jonkershoek forestry research station. South African Forestry Journal, Pretoria, n. 119, p. 35-40, Nov.1981. 